\title{
Analysis of Spots for Helicopter Saving in Mountain Area by Using GPS
}

\author{
Jong-Kook Park ${ }^{1}$, Eun-Seok Lee ${ }^{2}$, Jong-Hee Kim ${ }^{3}$, \\ Jeong-Su Kim ${ }^{4}$ and Jong-Bae Kim ${ }^{5 *}$ \\ 1,2,3,4,5 Graduate School of Software, Soongsil University, Seoul 156-743, Korea \\ 1eszero@gmail.com, ${ }^{2}$ geoles95@ssu.ac.kr, ${ }^{3}$ skyimo@hanmail.net, \\ ${ }^{4}$ kjjjsss1@gmail.com, ${ }^{5}$ kjb123@ssu.ac.kr
}

\begin{abstract}
The number of mountain climbers increases as leisure time expands and the aydreness of public health is promoted. However, thanks to physiographic features and carelessness of mountain climbers, the rate of accidents on the mountains also increases. When urgent accidents occur on the mountains, helicopters are uswally used for the emergencies adjusting to the difficult access. The objective of this study is to andlyze the spots for helicopter to land and take off when accidents occur on the mountains by using GPS to support decision-making for emergency saving system. The target area for this study was limited to Pucheon, Gyeonggi-do, in Korea. The spots for saving were classified into two such as landing spots and take-off spots for helicopter to respond to the emergencies on the practical site. Digital map, forest type map, and forest soils map were uised as fundamental data. This study was performed excluding factors such as direction of the wind, speed of the wind, etc. In the future, associated with DB from the Meteoxological Administration, more efficient analysis will be required.
\end{abstract}

Keywords: spatial informaton, GIS firsvaid helicopter, overlap function method

\section{Introduction}

Lately, due to the increase of the leisure time and the diversification of the hobby activities, there are active hiking activities, and as such, there are increasing hiking population every year. Also, due to the increasing hiking population, there are frequent disaster accidents within the forest thereof. In the event of such hiking accidents, when the medical support teams have difficulty in approaching the mountains, the mountains rescue helicopters can provide the emergency medical support $[1,2]$.

There are rescue activities being performed with the support of the National Emergency Management Agency, Ministry of National Defense, Korea Forest Service. However, each organization has its own rescue manual that is different from others' and in the emergency rescue and therefore, one has to work out in the field with the local weather and terrain context in reality $[3,4]$. The purpose of this study is to support with the helicopters' access and the effective mountains rescue activity, using the GIS spatial analysis method in the event of the mountains' rescue.

\footnotetext{
* Corresponding author. Tel. : +82-10-9027-3148. Email address: kjb123@ssu.ac.kr(Jong-Bae Kim).
} 
In this study, we implemented the strategic appointment of the site in consideration of the touchdown point sizes of the helicopters as per the data such as the ground gradient, vegetation characteristics.

\section{Analysis of Spots for Helicopter Saving in Mountain Area}

In analyzing the emergency medical support helicopter touchdown points, we set up the two analysis standard criteria: touchdown points when the helicopter can land at the rescue point and the dropping points for the emergency rescue team to use the rappel when the helicopter has difficulty in landing the rescue point. For analyzing the touchdown point and the dropping point, we utilized as fundamental data the digital map, forest type map, forest soil map, and the GIS overlap function.

\subsection{Touchdown Point Analysis}

We extracted 4 factors for the touchdown point factors: gradient, vegetation characteristics, terrain features, Helicopter Landing Zone (HLZs).

The gradient warrants the stability of the helicopter landing as per the sloping angle; for the purpose to extract the gradient, we extracted the hieight value and the gradient value using the digital map and changing the vector shape to DEM (Digital Elevation Model).

The vegetation characteristics can interfere with the helicopter landing with the forests' closure and the tree growth within the forest. Thus, we chose the un-stocked land region with no vegetation - the interfering factor-within the touchdown point. When there is vegetation, it is necessary to set up the tree height lessthan $30 \mathrm{~cm}$, which is the max.

Table 1. The Fundamental Data and Factor Values as per the Touchdown Point

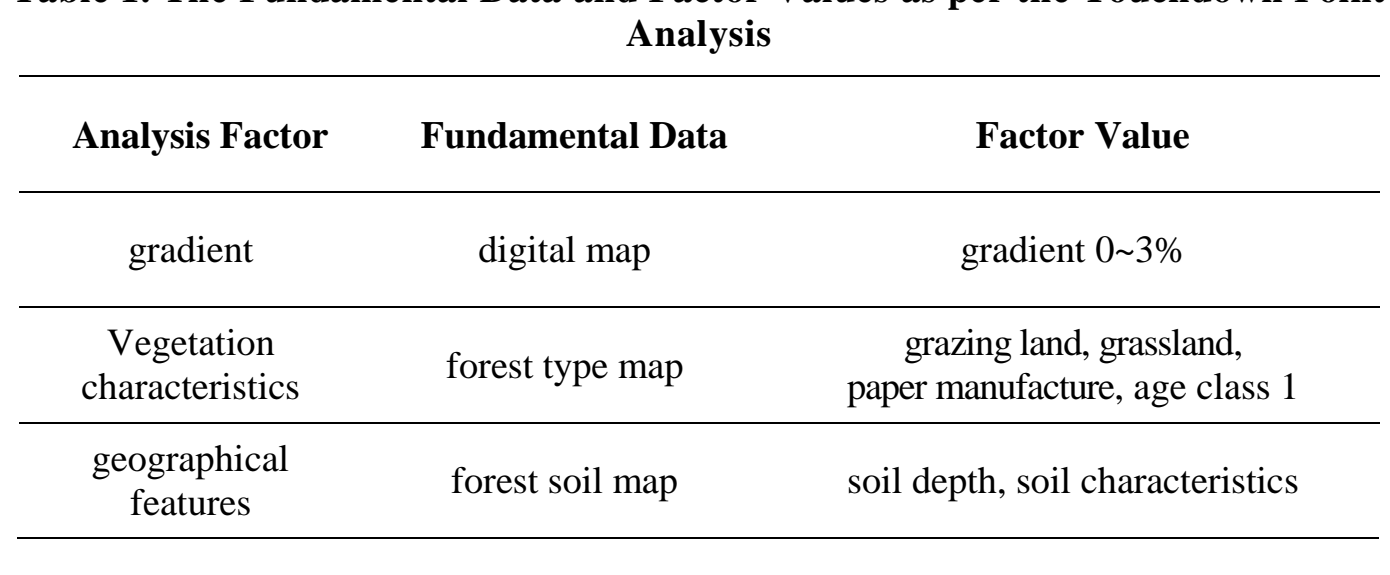

The he gh is not to interfere with the helicopter landing. For the vegetation characteristics' factor alye, we took the forest type map's age class and forest physiognomy as standard. The age class ranges from age class 1 through 10; and in general toward age class 10, the forest trees' growth periods get longer, with the tree heights higher as well. Thus, for the factor values, we set up the region with age class 1 trees in general, of the forest trees less developed with 1 10 year-old standing trees' crown area occupation ratio $\geq 50 \%$ stands. For the forest physiognomy, we set up as the factor values within the forest for paper making that are not used for the forest tree growth, such as the grazing lands with no trees and the grasslands and the roads, the rock lands, the cemeteries and the army facility sites, etc. 
In the geographical features, the solid area of the terrain with shallow soil depth is good for landing, so we extracted the factors utilizing the forest soil map with the soil characteristics as the standard, such as the soil depth and soil characteristics.

The helicopter landing zones (HLZs) require a certain size of area for the helicopter landing, and we calculated the area value as per the helicopter registration. The terrain analysis method by the US department of defense was utilized [5], which is a touchdown point size determining algorithm as per the helicopter registration.

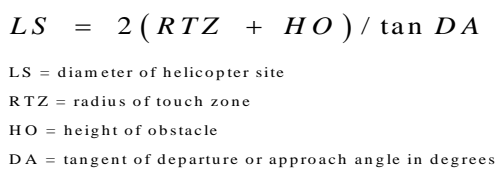

\subsection{Dropping Point Analysis}

We extracted 2 factors as the dropping point factors: the gradient and the vegetation characteristics.

The gradient and the vegetation characteristics are extacted with the same method as the touchdown point and the same method, but unlike the touchdown point, the helicopter doesn't directly land on the ground, and so we varied the factor alues. With the gradient as the factor value, we considered $0 \sim 10 \%$ as a good value and the limited the min. gradient value as the region, with 10 20\% as its limit.

With the vegetation characteristics, the forest floor area is the same as the touchdown point and we proposed for the factor value the good region with the tree height $0 \sim 2 \mathrm{~m}$, the note region as the tree height $2 \sim 5 \mathrm{~m}$.

For the tree height values, with the 1:5000 seale detailed forest type map, it is difficult to extract the overall forest tree height value by exracting the center value of each drawing and selecting the standard lot investigated region. Also, since there is no data implementing the tree height investigation targeting the national stands, we extracted the tree heights based on the per the species of the trees age class and tree height rating table of the major per the species of the trees stands yield table by the national forest and school. However, this shows the tree heights per site quality by utilizing the major species of the trees' age class and their site quality quotient, which nakes it difficult to judge the correct tree height.

Table 2. The Fundamental Data and Factor Value as per the Dropping Point Analysis

\begin{tabular}{|c|c|c|}
\hline Analysis factor Fundamental & good & notes \\
\hline digital map & $0 \sim 10 \%$ & 10 20\% \\
\hline
\end{tabular}

forest floor : grazing land, grassland, paper manufacture

vegetation
characteristics forest type map tree height $0 \sim 2 \mathrm{M}$ tree height $2 \sim 5 \mathrm{M}$

low density : low 
The low density of the vegetation characteristics is aerial photo three-dimensional sample or using the crown area density canonical measure to divide into the low, medium, high. When the density is low, the crown occupied area of the formed tree is $\leq 50 \%$ stands; the lower the dropping points' crown area density is, the lesser obstacles there will be in dropping, so I made this as the factor value.

\section{Results and Conclusions}

For the effective emergency medical support helicopter support, we extracted the touchdown point and the dropping point by utilizing the fundamental data and each of the factor values. For the correct analysis data in the future, we need to induce the analysis data that is correct and trustworthy by linking the weather values such as the wind direction and the wind speed that can influence on the helicopter. Also, for the correct data analysis of the tree height values applicable when the helicopter lands down, it has to precede measuring the correct tree height values of the region stands where accidents happen frequently

\section{References}

[1] J.-K. Park, E.-S. Lee, J.-H. Kim, J.-S. Kim and F.-B. Kim, "The Spatial Information based Mountains First Aid Helicopters' Location Selection Auto-analysis Mođel”, 2014 International Conference on Future Information \& Communication Engineering (ICEICE), (2014), pp. 373-376.

[2] J. H. Nah and M. H. Choa, "Analysis of Patents were Transported by 119 Helicopter from Mountain Accident Scenes in Seoul", The Korean Society of Eniergency Medicine, vol. 18, no. 6, (2007), pp. 450-457.

[3] H. G. Song, "The Analysis of Emergency Medical Transport by EMS Helicopter", The Korean Society of Emergency Medicine, vol ? no. 4, (1998), pp. 543-550.

[4] G. S. Jung, "The Problems of the Emetgency Rescue and First-aid and the Plan of Improvement in Korea", T. of Korean Institute of Fire Sci. \& Eng, Yol. 19, no. 2, (2005), pp. 81-92.

[5] U. S. Army, Terrain Analysis. U. S. FM 5-33 (1990).
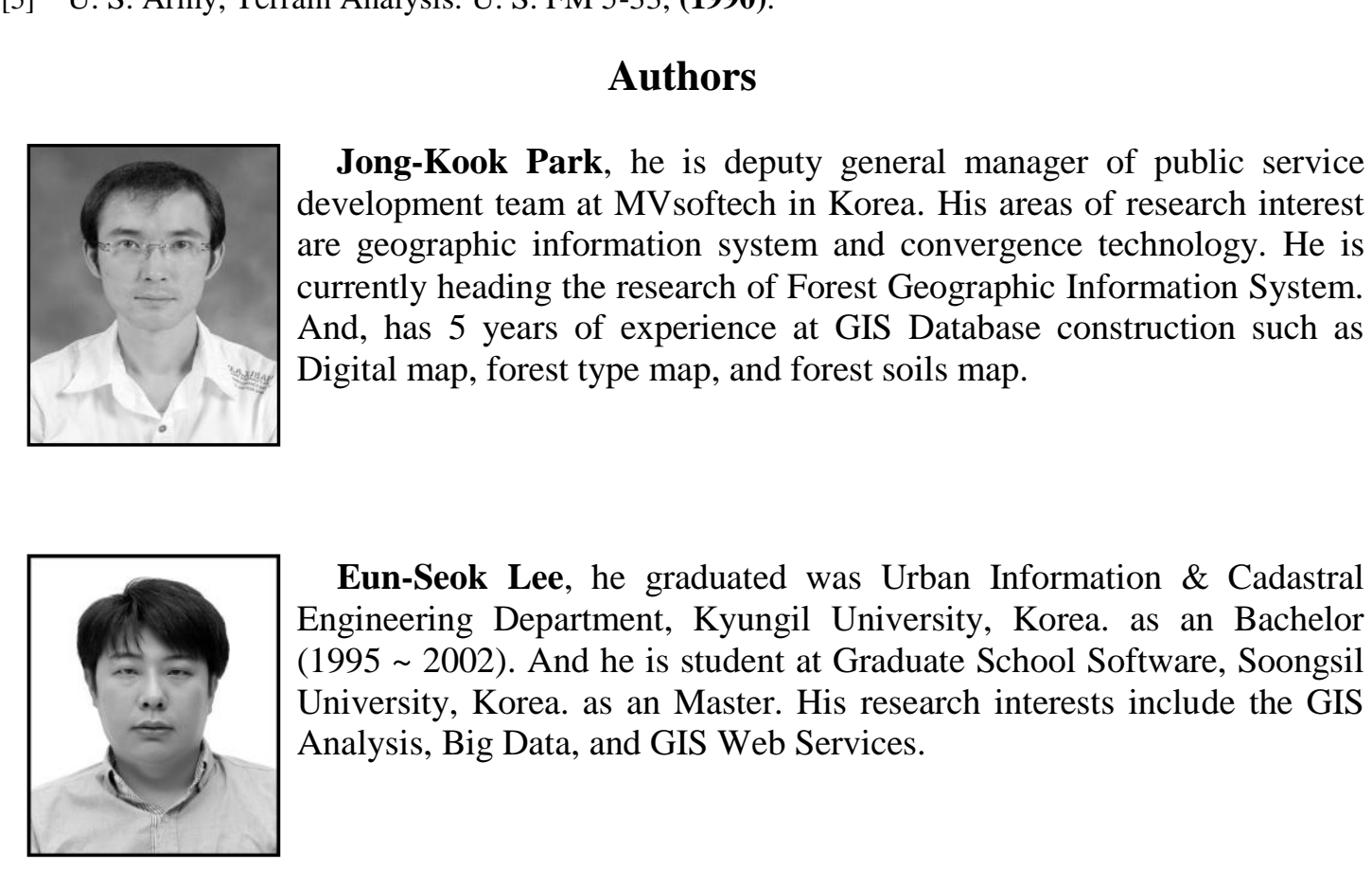

Eun-Seok Lee, he graduated was Urban Information \& Cadastral Engineering Department, Kyungil University, Korea. as an Bachelor (1995 2002). And he is student at Graduate School Software, Soongsil University, Korea. as an Master. His research interests include the GIS Analysis, Big Data, and GIS Web Services. 


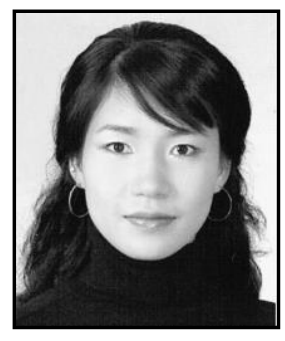

Jong-Hee Kim, she was Kyung-Hee university. She major was tourism Management. She is currently working on department of consultant in forcewin Inc.

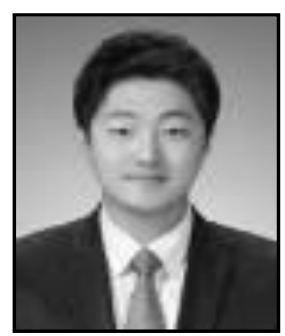

Jeong-Su Kim, he majored business administration at hanyang University until 2013, and now he studies software in graduate school of Soongsil University. He was studied business strategy in University, and he is studying Information Strategy Planning in graduate school. He already finished his paper about estimation optimal capacity of information system and participated many conferences. He worked at human resources department at business consulting firm as a internship.

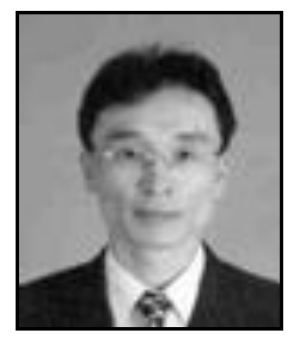

Jong-Bae Kim, he received his bachelor's degree of Business Administration in University of Seoul Seoul(1995) and master's degree(2002), doctor's degree of Computer Science in Soongsil University, Seoul(2006) Now he is a professor in the Graduate School of Software, Soongsil University, Seoul, Korea. His research interests focus on Software Engineering, and Open Source Software.

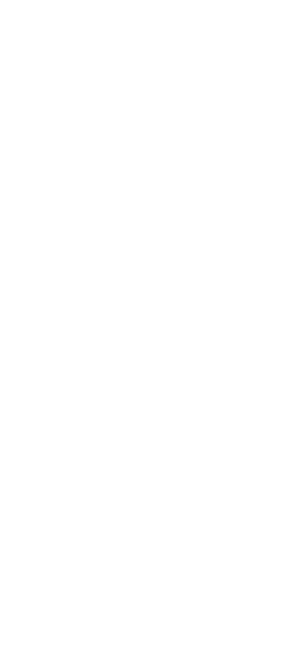


International Journal of Hybrid Information Technology

Vol.7, No.4 (2014)

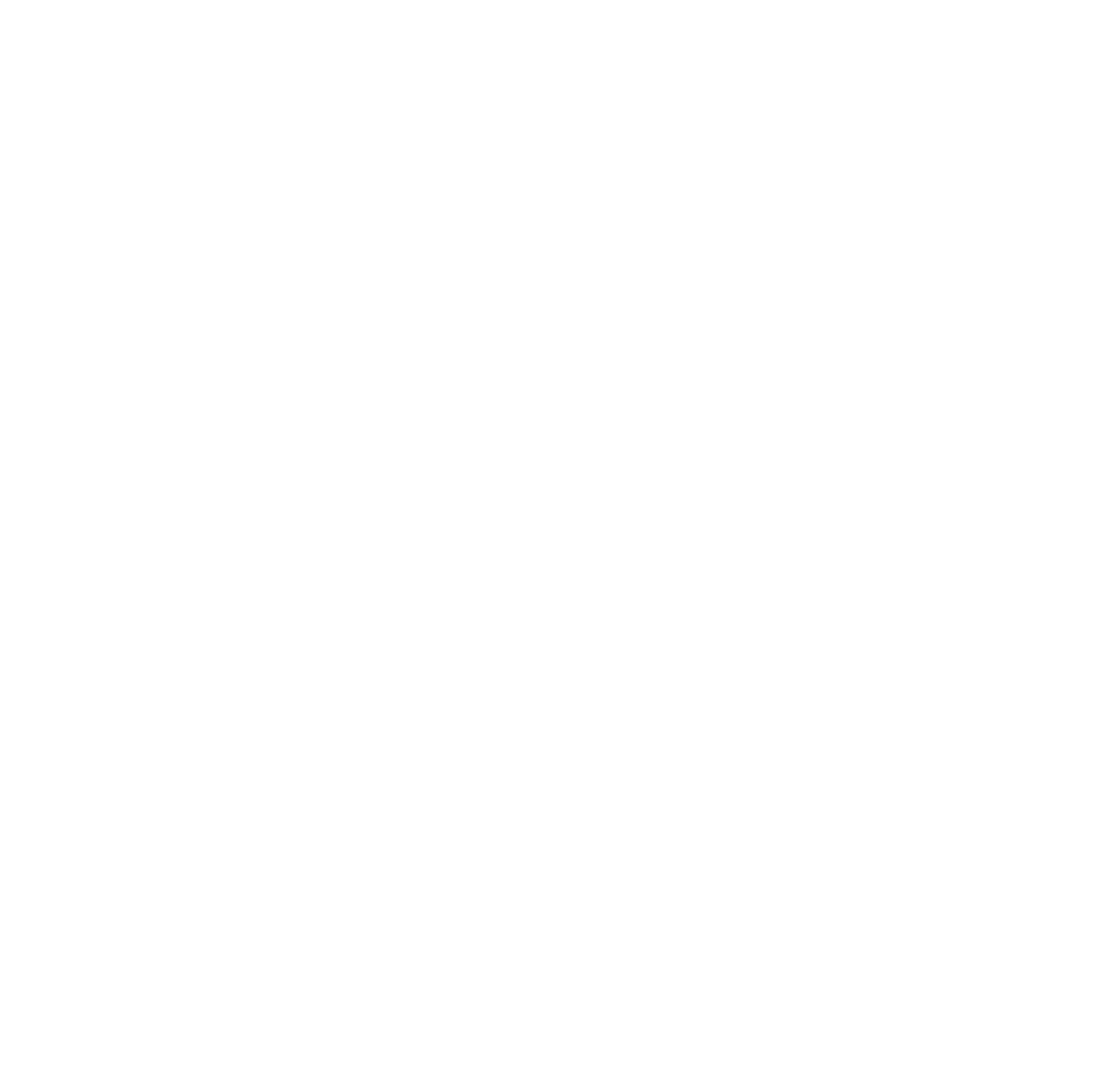

